\title{
Getting retting better by bacterial blending
}

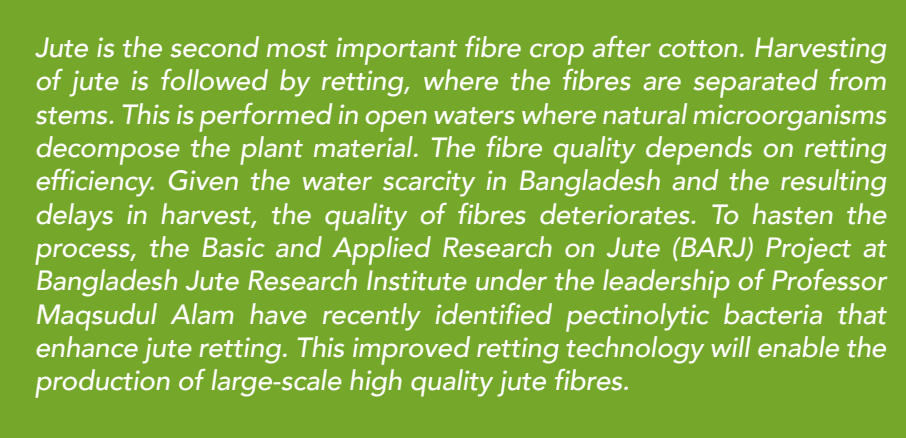

ute is an important cash crop cultivated and processed for the plabres. Following jute harvest, called retting whereby the stalls are submerged in water bodies. This allows natural decomposing of the stems via water-based microorganisms, to release fibres. The microorganisms in the water bodes possess enzymatic activites plant materials. Unfortunately, the scarcity of water in Bangladesh results in havesting delays, forcing the farmers to use the same water bodies for retting repeatedly, resulting in poor quality retting process and the water efficiency, alternative procedures are necessary. $A$ team in the BAR project have recently discovered a consortia of bacteria that act efficiently to digest jute stalks and release fibres. This environmentally friendly technology can be used in industrial scale retting to improve jute fibre quality.

\section{NATURAL DIGESTION}

Microorganisms are around

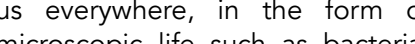
fungicopic life such as bacteria, few. There are some good one and bad ones, depending on the microorganism and what it affects.

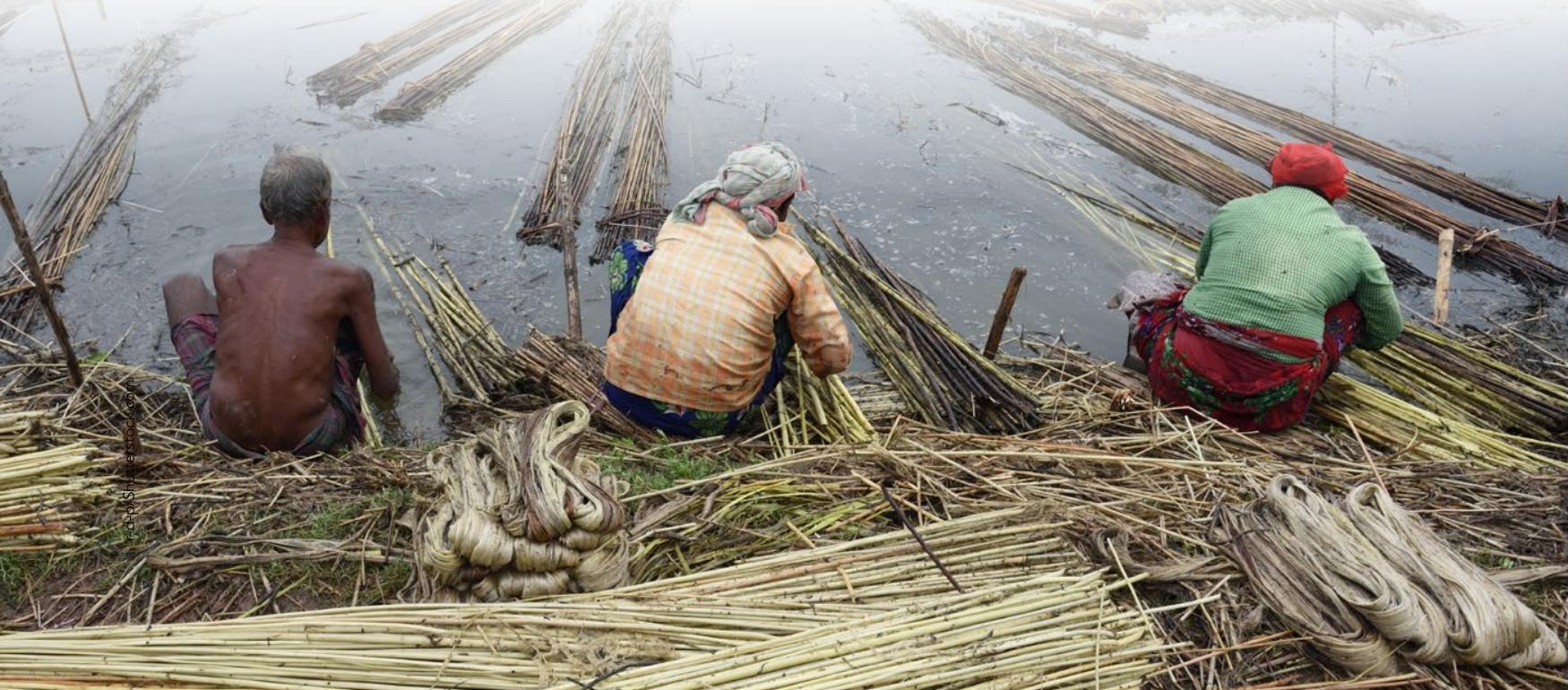

Retting is the process by which unwanted compons
and hemicellulosess) are removed from jute stems.

In a teaspoon of soil, there is thought to be more than one billion bacteria. These bacteria could be harmful or helpful, depending on the plants that grow in the soll. many bacteri that hel, hegre organic matter such as plants.

Natural decomposition of organic plant matter occurs in the environment with the help of microorganisms. This is process which is essential for the recycling of carbon, nitrogen and other nutrients in the ecosystem. Decomposition of plant materia requires the chemical activity of microorganisms. Bacteria release numerous enzymes (specialised promplex substances present in plants to break them down into smaller particles. These smaller particles are then either consumed by the bacteria to help them reproduce or recycled back into the ecosystem. If more organic matter is fed into the ecosystem then the bacteria rapidly multiply and increase in number as they decompose the plant. This digestion of organic matter is no only useful for the microorganism, but it can also be useful for processing of plant material for taken advantage of in the jute processing industry.

\section{LETTING RETTING WORK}

Once jute plants are harvested, an important process is to separate the jute fibres from the stems, in a process called retting. After inting, the fibres are subsequently removed from the stems, manufacture various jute produ to manufacture various jute products. the first downstream step after harvesting of the crop, which is important to initiate the whole fibre extraction process.

Jute fibres are embedded in the structure of the jute stem with the help of various structural

Once jute plants are harvested, an important process is to separate the jute fibres from the stems, in a process called retting.

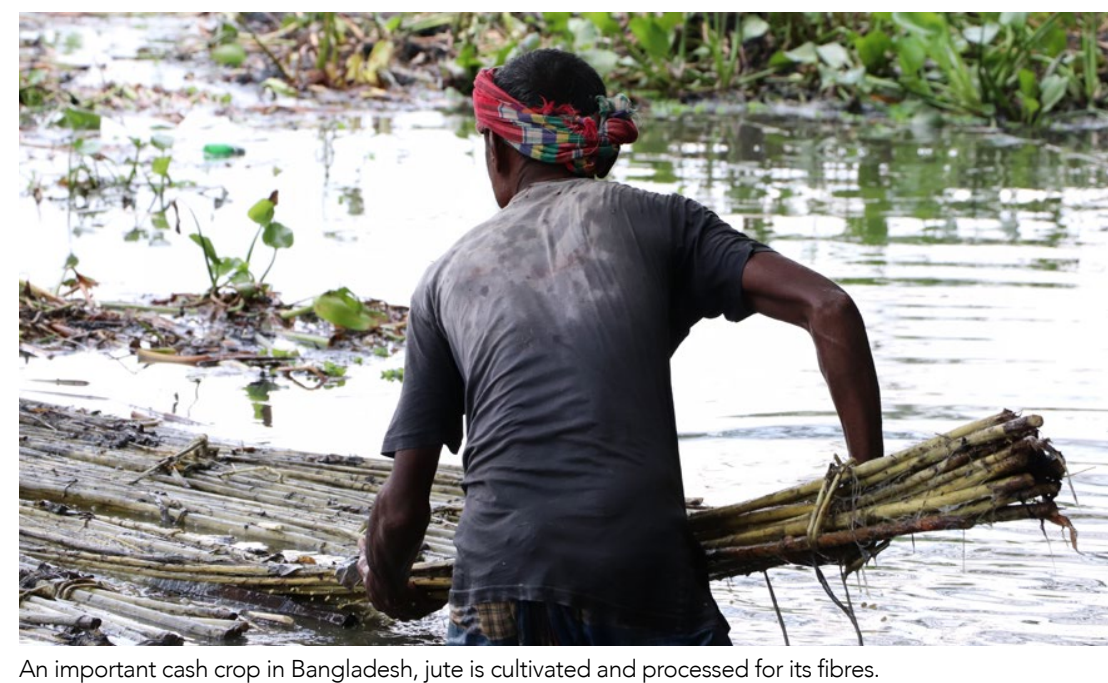




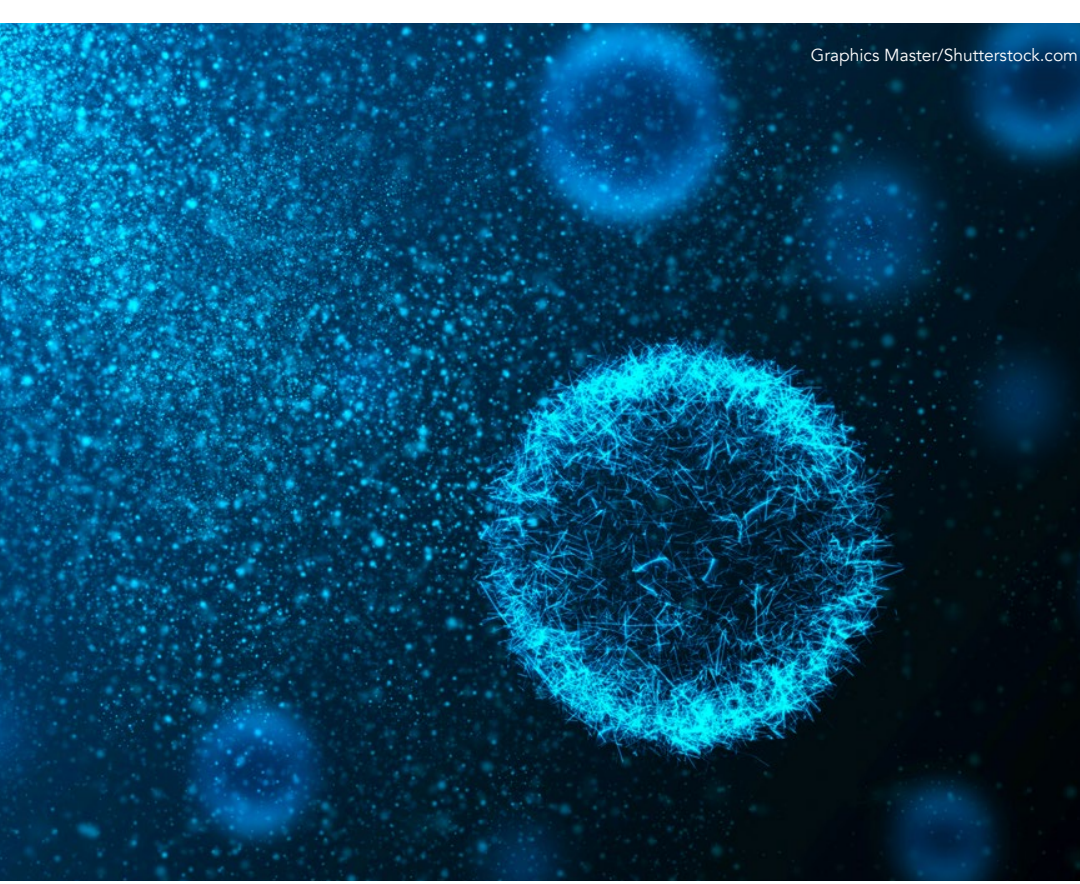

BARJ Project identified potential retting microbes from retting liquor.

Retting can be carried out either by given the scarcity of water resources chemical, water-based microbial, enzymatic or dew methods. Of reuse the same water bodies for these, apart from the water-based retting. This depletes the water of method, the other processes its microorganisms, mainly bacteria, use toxic chemicals or are very thereby making the water of poor expensive. Getting the efficiency quality for the purpose of retting.
and timing of retting perfect is Retting would have to proceed for

water samples in Bangladesh. They studied the digestive properties of various isolated bacteria, in particular their pectinase, xylanase activities. The (digests cellulose) activities. The enzyme activities were first tested on artificia substrates (pectin, hemicellulose Bacteria which contained pectinase (pectinolytic bacteria) and xylanase activity, but were devoid of cellulase activity were considered to be efficient digestors for the purpose of microbial retting. A total of 45 bacterial isolates were identified in these water samples using molecular biological approaches. From these, the authors the ested combinations of ten different bacterial isolates to investigate whether bacterial consorti possessed better enzymatic activity esting the enzyme activ lesting the enzyme activity on were tested with jute samples to check their ability to digest plan material.

Three combinations of pectinolytic bacteria were identified that lowered the retting duration from $18-21$ days to 10 days, and also yielded high quality jute fibres in small scale and large-scale process resulted not easy, yet it is the most
important step important step the quality of the fibre. Over-retting or under-retting of jute results in fibres that are rough, lack lustre and not as strong as they should . This proves to be damaging to the jute industry.

The water-based method of retting is dependent on the activity of water body These microorganism release enzymes such as pectinases (that breakdown pectin) and xylanases (that breakdow hemicellulose); this digestion of plant cell wall compounds releases jute fibres from the stems. However,
This technique using retting microbes now be used in large-scale industrial processes, without damaging the environment with toxic chemicals.

in $m$ prove im $\mathrm{pr}$ r $\mathrm{v}$ e
strength, colour and quality. The study therefore identified novel method of using bacterial consortia to facilitate longer times, therefore resulting need to identify new methods to make the retting process more environmentally friendly.

\section{RETTING WITH}

ACTERIAL BLENDING

work, the BARJ Project at Bangladesh Jute Research populations in different jute retting in fibres that are not of very good quality. There has been an urgent
Research Objectives

Acute shortage of water and environmental pollution created from the conventional methods of jute retting

\section{References}

Hasan, R. Aktar, N., Kabir, S.M.T. et al. (2020) Pectinolytic bacterial consortia reduce jute retting period and improve fibre quality. Nature Scientific Reports, 10, 5174. https://doi.org/10.1038/s41598-020-61898-z

\section{Personal Response}

How soon can this process be adapted for application in the field?

II Before any process can be applied to the field it must be economically viable, socially acceptable as well as environmentally friendly. Considering these factors, we are developing a package which is easy to use at a margina farmer's level. We are testing different cheap materials such as rice bran, sugarcane husk, wheat bran, etc., which can be used as an effective carrier substance for long term storage of the consortia. We are going to a large scale field trial using consortia under farmer's fields in new and challenging situations. It will take 2-3 jute growing seasons to
complete a technology package for marginal farmers.

\section{Can traditional methods be changed easily to adopt this process?}

II The traditional retting method of jute has been universally practiced since the initiation of jute cultivation. So farmers may not agree with a change in the method they know and practice and which they see working. Why would they pay money for something they don't know? We aim to apply the technology practically in front of them and let them see with their own eyes how much more benefit they can get with such an application. Compared to the traditiona approach, our novel method of using bacterial consorta is more exfective in terms of reduction of retting period with minimum amounts of water and improved fibre quality. It is expected that farmers in the area of water
scarcity will show their interest to accept this new process easily.

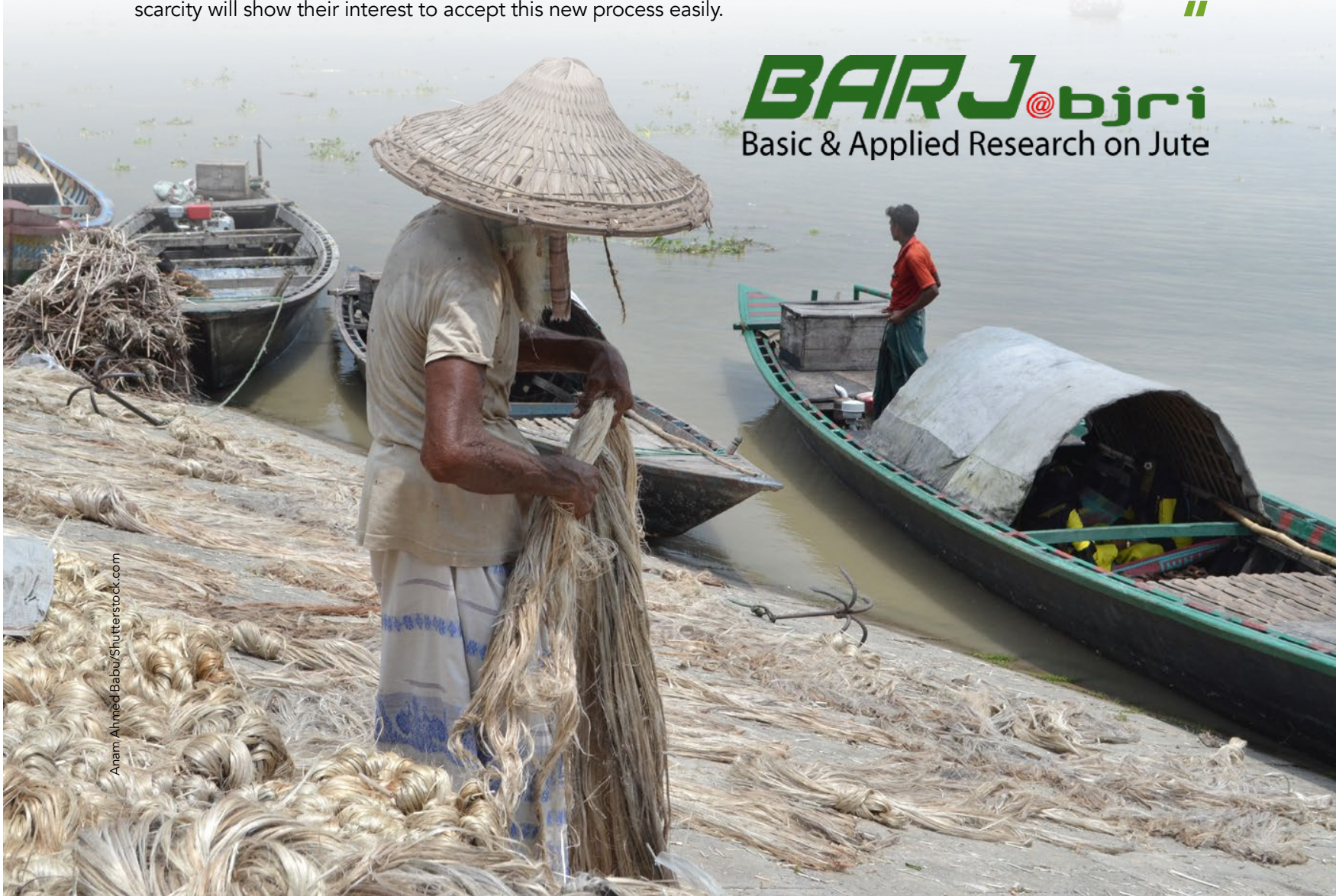

